\title{
Assisted sintering of silver nanoparticle inkjet ink on paper with active coatings
}

\author{
Thomas Öhlund ${ }^{* 1}$, Anna Schuppert ${ }^{2 *}$, Britta Andres ${ }^{1}$, Henrik Andersson ${ }^{3}$, Sven Forsberg ${ }^{1}$, Wolfgang Schmidt ${ }^{2}$, \\ Hans-Erik Nilsson ${ }^{3}$, Mattias Andersson ${ }^{4}$, Renyun Zhang ${ }^{1}$ and Håkan Olin ${ }^{1}$ \\ ${ }^{1}$ Department of Natural Sciences, Mid Sweden University, SE-85170 Sundsvall, Sweden. E-mail: thomas.ohlund@gmail.com
}

${ }^{2}$ Schoeller Technocell GmbH \& Co. KG, Burg Gretesch, 49086, Osnabrück, Germany

*Institut Charles Gerhardt de Montpellier - UMR 5253, 34095 Montpellier Cedex 5, France

${ }^{3}$ Department of Electronics Design, Mid Sweden University, SE-85170 Sundsvall, Sweden

${ }^{4}$ Department of Natural Sciences, Digital Printing Center, SE-89118, Örnsköldsvik, Sweden

Inkjet-printed metal films are important within the emerging field of printed electronics. For large-scale manufacturing, low-cost flexible substrates and low temperature sintering is desired. Tailored coated substrates are interesting for roll-to-roll fabrication of printed electronics, since a suitable tailoring of the ink-substrate system may reduce, or remove, the need for explicit sintering. Here we utilize specially designed coated papers, containing chloride as an active sintering agent. The built-in sintering agent greatly assists low-temperature sintering of inkjet-printed AgNP films. Further, we examine the effect of variations in coating pore size and precoating type. Interestingly, we find that the sintering is substantially affected by these parameters.

\section{Introduction}

The interest in printed electronics and other printed functionalities is considerable worldwide. In contrast to traditional subtractive photolithography- and etching processes, the printing process is purely additive, which means less material waste and a reduced need for processing chemicals. This results in cost savings and environmental advantages, in particular when large area coverage is desired. Additionally, printing processes have good compatibility with flexible substrates such as plastic films and paper. Applying electronic- or other functionality on flexible, low-cost substrates, across large areas in roll-to-roll processes, enables novel applications with large potential. Among the many important applications for printed electronics are photovoltaic devices ${ }^{1}$, sensors ${ }^{2}$, displays ${ }^{3}$ and radio-frequency identification (RFID) tags ${ }^{4}$. Many types of functional materials can be formulated into printable inks, including electrically conducting ${ }^{5}$, semiconducting ${ }^{6}$ and insulating materials ${ }^{7}$, as well as materials with magnetic ${ }^{8}$, optical ${ }^{9}$, chemical ${ }^{10}$ or biological ${ }^{11}$ functions. When comparing printing methods, inkjet allows comparably small feature size, less than $40 \mu \mathrm{m}$ on some substrates ${ }^{12}$. It is capable of covering large areas with simple and cost-effective setups. Furthermore, the non-contact nature of deposition allows it to be used for delicate and pressure-sensitive surfaces. The ink formulation is relatively challenging. To be reliably jetted, properties such as viscosity, surface tension, volatility and particle size need to be well controlled. To avoid aggregation, the particles are typically stabilized using polymers that adhere to the surfaces. Depending on the specific polymers and electrical charges in the system, the stabilization may be either steric, electrostatic or a combination of both (electrosteric) ${ }^{13}$. Some of the most common stabilizing polymers are polyvinylpyrrolidone (PVP) and polyvinyl alcohol (PVA) ${ }^{14}$.
Electrically conducting layers are important since they are included in most applications of printed electronics. Although conductive inkjet inks may be formulated from several classes of materials, including conductive polymers ${ }^{15}$, carbon-based materials ${ }^{16,17}$, and metal nanoparticles (NPs) ${ }^{18-20}$. The metal NP inks are particularly suitable when high conductivity is required, for example when printing antennas ${ }^{21}$ and circuit board conductors ${ }^{22,23}$.

Paper-based substrates for printed electronics are interesting for several reasons. Environmental friendliness, flexibility and low cost are the key benefits. The physical and chemical properties may be altered by chemical additives or changes in materials and processes. Therefore it is possible to tailor the paper or coating, adapting it to a specific functional ink or application. Uncoated paper is generally too porous and rough to be compatible with most functional inks, which means that coatings need to be applied. The properties of the coating are particularly important, such as pore size, surface roughness, absorption rate, mechanical stability and surface chemistry. These properties must be controlled in order to prevent problems occurring within the printed layer. To optimize the properties, the entire system must be understood and accounted for. This system includes substrate, ink rheology and composition, printing- and sintering method, as well as the intended application.

Sintering of the NP films is typically necessary to achieve low resistivity. Roll-to-roll processes using low-cost plastic- or paperbased substrates require sintering that is high-speed compatible and harmless to the sensitive substrates. Among the metal-based inks, silver NP inks are most widely used due to a low reactivity in air, the possibility of low temperature sintering, as well as a commercial availability. It is known that low-temperature sintering of certain AgNP inks can be facilitated by the presence of chloride. In most cases, researchers have post-treated printed patterns with liquid or vapor that carries the chloride. In some cases they have pre-treated 
substrates before printing. However, the design and manufacturing of paper substrates that actively facilitate low-temperature sintering of AgNP films has not been shown previously.

Here we demonstrate low-temperature sintering facilitated by custom-designed coated papers. The concept is to incorporate the sintering agent as an integral part of the mesoporous paper coating, to achieve low-temperature sintering without the need for chemical pre-treatment or post-treatment. A small concentration of chloride is added in the coating during the paper manufacturing. During the ink deposition and solvent uptake, chloride migrates into the AgNP film, concentrates and facilitates the sintering. Further, we show that the sintering is impaired by increasing the coating pore size, but greatly enhanced by using a porous $\mathrm{CaCO}_{3}$ precoating.

\section{Experimental}

\section{Base paper manufacturing}

Eucalyptus was beaten as a $5 \%$ aqueous suspension (thick matter) using a refiner to a beating degree of $36^{\circ} \mathrm{SR}$. The concentration of eucalyptus fibers in the thin matter was $1 \mathrm{wt} \%$. The thin matter was supplemented with internal sizing agent (alkyl ketene dimer, AKD, 0.5 wt\%), wet-strength agent (polyamine-polyamide epichlorhydrin resin, $\mathrm{Kymene}^{\circledR}, 0.4$ wt\%) and filler (ground $\mathrm{CaCO}_{3}, 10$ wt\%). The quantities are given with respect to the fibre mass. The thin matter, with a $\mathrm{pH}$ adjusted to approximately 7.5, was transferred from the headbox onto the screen portion of the paper machine, forming sheets by dewatering the web. The paper was further dewatered in the press section, followed by drying using heated rollers. A base paper was obtained with a grammage of $160 \mathrm{~g} \cdot \mathrm{m}^{-2}$ and a moisture content of approximately $7 \%$.

\section{Precoating preparation and application}

\section{Sealed PE precoating}

A low density PE film (LDPE, $0.92 \mathrm{~g} \cdot \mathrm{cm}^{-3}$ ) was applied to the base paper using melt extrusion lamination. The laminator used a speed of $250 \mathrm{~m} \cdot \mathrm{min}^{-1}$, resulting in a PE film thickness of approximately $20 \mu \mathrm{m}$.

\section{Porous precoating}

Ground calcium carbonate $\left(\mathrm{GCC}, \mathrm{d}_{50 \%}=0.7 \mu \mathrm{m}\right)$ was mixed with styrene acrylate in 1:1 ratio by volume. The mix was applied to the base paper using blade coating ${ }^{24}$, resulting in a layer thickness of approximately $20 \mu \mathrm{m}$.

\section{Mesoporous absorption coating}

\section{Preparation}

Coating dispersions were prepared, using boehmite alumina pigment powder ((AlO $(\mathrm{OH})$, Sasol Disperal, $30 \mathrm{wt} \%)$ dispersed in water. The agglomerates were ground (IKA Ultra-Turrax) and electrostatically stabilized by addition of acetic acid ( 3 wt\%). A small amount of chloride salt ( $\mathrm{KCl}, 0.3 \mathrm{wt} \%)$ was added. PVA was used as binder (Kuraray Mowiol 40-88), and boric acid as hardener. The weight ratio of pigment:binder:hardener was 90:8:2. Six different dispersions were prepared, where only the pigment was varied. Each dispersion used a pigment with a specific crystallite size. The pigments used were (in order of increasing crystallite size): Sasol Disperal series HP8, HP10, HP14, HP16, HP18 and HP22. The number after HP refers to the nominal crystallite size in nanometers, according to the manufacturer.

\section{Application}

Each coating mix was applied on top of each precoating using a wirebar applicator. The coatings were dried in an oven for 15 minutes at $80{ }^{\circ} \mathrm{C}$ resulting in a coating thickness of approximately $35 \mu \mathrm{m}$. This way, two series of papers were manufactured, each series with a controlled pore size variation in six steps. Series 1 had a sealed PE precoating (barrier). Series 2 had a porous $\mathrm{CaCO}_{3}$ precoating. The paper with HP8 coating on $\mathrm{CaCO}_{3}$ precoating had more coating surface defects than the others, and was therefore excluded from further use. Cross sections of papers from both series are shown in Fig. 1.

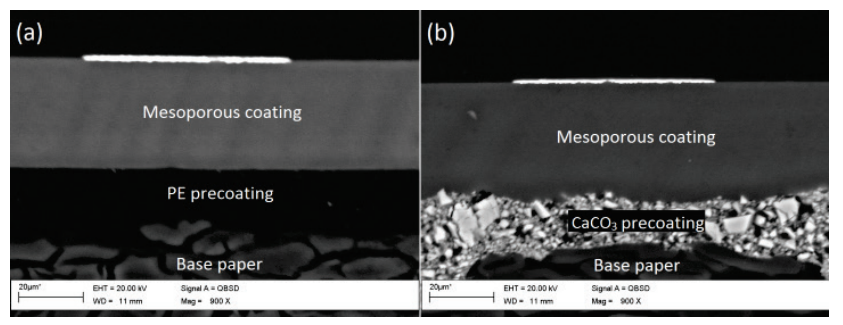

Fig. 1 Cross sections showing the construction of the two paper series (scanning electron microscopy, SEM). The topmost white layer is a printed silver layer. Only the upper part of the base paper is seen. (a) PE precoating. (b) $\mathrm{CaCO} 3$ precoating. The scale bars are $20 \mu \mathrm{m}$ wide.

\section{Mesoporous coating characterization}

Pore size characterization was performed using mercury porosimetry (Pascal 440 porosimeter for the $3-50 \mathrm{~nm}$ range, Pascal 140 porosimeter for the $50 \mathrm{~nm}$ to $100 \mu \mathrm{m}$ range). Surface roughness was evaluated using atomic force microscopy (AFM, Nanosurf Easyscan2, tapping mode). Surface $\mathrm{pH}$ values were measured using a flat membrane $\mathrm{pH}$ electrode (Mettler Toledo 403-34-S7/165), 20 minutes after deposition of a water film on top of the coating. The measurements were repeated 3 times at different spots. Elemental composition analysis was performed using energy dispersive spectroscopy (SEM-EDS, Jeol JSM-6610LV with Oxford INCA). For scanning electron microscopy (SEM), Zeiss Merlin and Zeiss EVO 50 microscopes were used.

\section{Additional substrates for comparison}

Polyethylene terephthalate film (PET, Mitsubishi Hostaphan RN, 100 $\mu \mathrm{m})$ was used as a comparative non-absorbing, nonporous flexible substrate. Before printing, it was ultrasonicated in water for 15 minutes at $60{ }^{\circ} \mathrm{C}$, rinsed in ethanol, distilled water, and dried. For control experiments, two additional substrates were used. 1) A lightweight coated paper (SCA LWC GC80) with a coating consisting of $\mathrm{CaCO}_{3} /$ kaolin clay with styrene butadiene binder. No coating $\mathrm{Cl}$ content was detectable by SEM-EDS. 2) A HP16/PE paper, on which additional chloride was added by depositing $0.1 \mathrm{M} \mathrm{HCl}$ (meyer rod coating with $10 \mu \mathrm{m}$ wet film thickness), followed by drying at $60{ }^{\circ} \mathrm{C}$. These substrates were used to evaluate sintering implications of 1) surface presence of $\mathrm{CaCO}_{3}$ (with absence of $\mathrm{Cl}$ ) and 2) surface presence of $\mathrm{Cl}$ (with absence of $\mathrm{CaCO}_{3}$ ). 


\section{Inks and printing}

The conductive patterns were inkjet-printed using a commercially available silver NP ink (CCl-300, Cabot Corporation), containing 20 wt\% AgNP, dispersed in a mix of ethanol and ethylene glycol. The size range of the NPs were assessed using HR-SEM to 20-70 nm, with most of the NPs belonging in the $30-40 \mathrm{~nm}$ range.

The colloidal stability of the dispersion at various $\mathrm{pH}$, and in the presence of various salts, was examined with a turbidimeter (Hach Ratio XR), according to the following procedure: The ink was diluted with ethanol (analytical grade) in a ratio of 1:25. $50 \mu$ l of the diluted ink was added to $30 \mathrm{ml}$ of the test solution. Immediately after mixing, the $\mathrm{pH}$ of the solution was measured and the turbidity was measured as a function of time. As reference test solutions, ethanol and deionized water were used. To vary $\mathrm{pH}, \mathrm{CH}_{3} \mathrm{COOH}$ (>99.8\%, Fluka) or $\mathrm{NaOH}$ (>99\%, Riedel-de Haën) of various concentrations were used. Salts tested were $\mathrm{CaCO}_{3}, \mathrm{Na}_{2} \mathrm{CO}_{3}, \mathrm{NaHCO}_{3}$ and $\mathrm{CaCl}_{2}$ at a concentration of $0.01 \mathrm{M}$ and $0.1 \mathrm{M}$.

A piezoelectric inkjet printer (Dimatix 2831) was used to print horizontal conductors of nominal dimension $20 \times 0.4 \mathrm{~mm}$ (Supplementary Fig. S1). An ink cartridge with $10 \mathrm{pL}$ drop volume was used (Dimatix 11610). For the droplet actuation, a voltage of $24 \mathrm{~V}$ was applied with a waveform supplied by the manufacturer. The drop spacing was set to $20 \mu \mathrm{m}$; nozzle- and platen temperatures were kept at a controlled room temperature of $22{ }^{\circ} \mathrm{C}$. The printed conductors were thoroughly dried at $60{ }^{\circ} \mathrm{C}$ for complete solvent evaporation. Material characterization of the silver films was made with X-ray photoelectron spectroscopy (XPS, Kratos AXIS UItra DLD).

\section{Sintering}

Sintering was performed by stepwise heating to $90,110,150$ and 180 ${ }^{\circ} \mathrm{C}$ for 5 minutes at each temperature, using a heat chamber with air circulation fans (Pol-eko SLW53). Electrical resistance was measured after each temperature step. The upper temperature limit was chosen because it was the maximum that could be used without conductor failure due to cracking of the PE precoating. The maximum temperature used is above the melting point of $\mathrm{PE}$ and was usable only with careful handling of those papers. The papers using $\mathrm{CaCO}_{3}$ precoatings (as well as the LWC paper and the PET film) resisted normal handling (bending etc.) for all temperatures without conductor failure. However, the papers were subject to permanent discoloration above $150^{\circ} \mathrm{C}$.

\section{Resistance measurements and resistivity calculations}

Conductor resistance was measured with 4-point probes, using a source-meter in current source mode (Keithley 2611A). For calculating an average, 14 conductors were measured for each substrate. The volume resistivity of the printed layer was calculated from the measured resistance by using the well known definition $R=$ $\rho^{*} \mathrm{~L} / \mathrm{A}$ where $\rho$ is the resistivity, $R$ is the resistance, $L$ is the conductor length and $A$ is the cross-sectional area of the conductor. To calculate the cross-sectional area, the layer thickness was determined with AFM after sintering to approximately $0.30 \mu \mathrm{m}$. For the conductor width and length, the nominal printing pattern values of $400 \mu \mathrm{m}$ and $20 \mathrm{~mm}$ were used in the calculations.

\section{Results and discussion}

\section{Characterization of absorption coatings}

Pore size distribution

Fig. 2 shows the pore radius distributions of the different papers, measured with mercury porosimetry. We define the characteristic pore radius of each paper as the maximum of each corresponding distribution. This is since the characteristic pore radius then represents the pores with the largest contribution to the total pore volume of the coating. The range of characteristic pore radii was 9-32 $\mathrm{nm}$ for the PE precoated papers and $16-38 \mathrm{~nm}$ for the $\mathrm{CaCO}_{3}$ precoated papers (Supplementary Table S2). Although the same coating dispersions were used for both series, slightly larger pore sizes resulted on the $\mathrm{CaCO}_{3}$ series. This was likely caused by an increased flocculation of the coating pigments during the coating application.

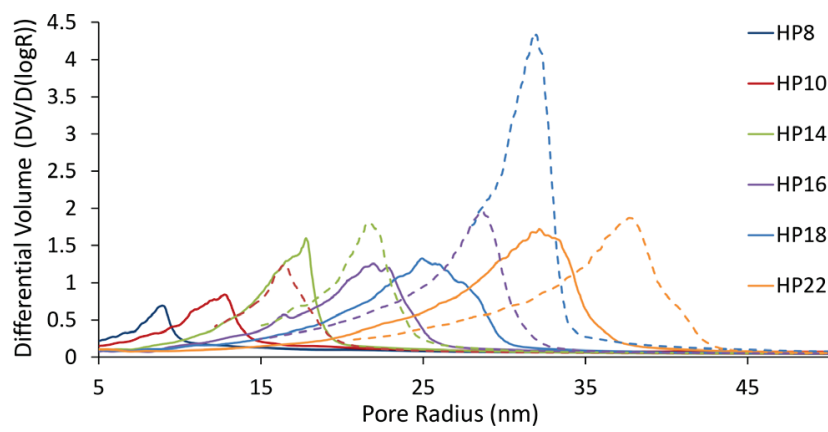

Fig. 2 Pore radius distributions of the different mesoporous absorption coatings on top of a PE precoating (solid) or a $\mathrm{CaCO}_{3}$ precoating (dashed).

\section{Surface roughness}

Surface roughness characterization was performed with AFM on a selection of papers using PE- as well as $\mathrm{CaCO}_{3}$ precoating. The characterized absorption coatings were the ones with the smallestand largest pigment size (HP10 and HP22, respectively). Surface roughness ( $\mathrm{Sq}$, root mean square) measured over $20 \times 20 \mu \mathrm{m}$ was 24 $39 \mathrm{~nm}$ (Supplementary Fig. S3). The coatings with HP22 pigments had a larger surface roughness on the short scale compared to HP10 pigments. This is expected and consistent with the porosimetry results (Fig. 2), since larger coating pigments should result in increased high-frequency roughness and characteristic pore size. Therefore it is also expected that coatings with intermediate pigment size (HP14-HP18) have intermediate surface roughness. Height distributions show that surface peaks measured perpendicular to a fitted average plane are well below the thicknesses of the dried silver films (Supplementary Fig. S4). Therefore the surface roughness should be sufficiently low to allow continuous film formation on all papers in the study. Surface roughness of the substrates used for comparison were measured as well. The LWC paper had Sq $=56 \mathrm{~nm}$ and the PET film Sq $=7 \mathrm{~nm}$ (Supplementary Fig. S3). Fig. 3 shows high magnification SEM images of the surfaces of $\mathrm{HP} 10 / \mathrm{PE}, \mathrm{HP} 10 / \mathrm{CaCO}_{3}$, $\mathrm{HP} 22 / \mathrm{PE}$ and $\mathrm{HP} 22 / \mathrm{CaCO}_{3}$ papers. The images confirm that the larger pigments give rise to a higher surface roughness and pore size, and that the $\mathrm{CaCO}_{3}$ precoating increases the roughness/pore size slightly. 


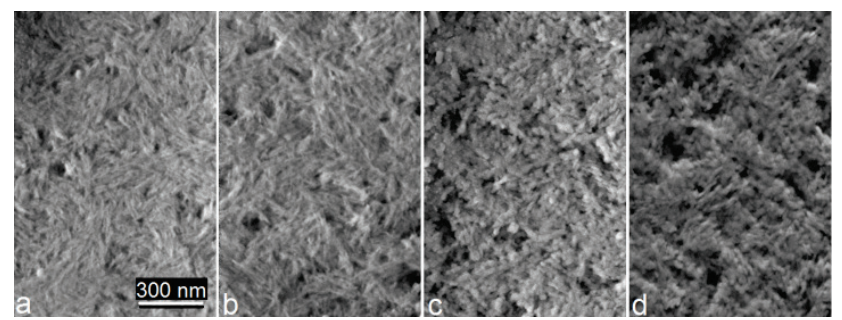

Fig. 3 Morphology of mesoporous coatings on active papers (SEM). The HP10 papers have a smoother surface and smaller pores compared to the HP22 papers. The $\mathrm{CaCO}_{3}$-precoated papers have slightly larger surface roughness and pore size than the corresponding PE-precoated papers. a) HP10/PE. b) HP10/CaCO3. c) HP22/PE. d) HP22/CaCO3.

\section{Surface chemistry}

Surface composition analysis was performed using SEM-EDS on the same selection of papers that was characterized with AFM (HP10/HP22 absorption coating, combined with $\mathrm{PE} / \mathrm{CaCO}_{3}$ precoating). Fig. 4 shows that the largest spectrum peaks correspond to the elements $\mathrm{Al}$ and $\mathrm{O}$, obviously due to the alumina pigment NPs. Note further that the surface on papers with $\mathrm{CaCO}_{3}$ precoating contained detectable amounts of $\mathrm{Cl}$ and $\mathrm{Ca}$. Since $\mathrm{Ca}$ was not contained in the top coating dispersions, but indeed present in the porous precoating, $\mathrm{Ca}^{2+}$ has presumably diffused through the mesoporous top coating during its application and drying. This is reasonable since $\mathrm{CaCO}_{3}$ reacts with the acidic top coating dispersion according to $2 \mathrm{H}^{+}+\mathrm{CaCO}_{3} \rightarrow \mathrm{Ca}^{2+}+\mathrm{H}_{2} \mathrm{O}+\mathrm{CO}_{2}$. The detected $\mathrm{Cl}$ is expected due to the addition of $\mathrm{KCl}$ in the coating dispersions. With a quantitative EDS analysis, surface-near concentrations for the $\mathrm{CaCO}_{3}$ series were estimated to $0.3-0.5 \mathrm{wt} \%$ of $\mathrm{Cl}$ and approximately 0.4 wt\% of Ca (Supplementary Table S5). The values are approximate since quantitative EDS analysis cannot be expected to be accurate for porous surfaces. For the PE series, Ca could not be detected and the $\mathrm{Cl}$ concentration was too low to determine quantitatively. Note that higher surface concentration of $\mathrm{Cl}$ was found for the $\mathrm{CaCO}_{3}$ precoating series, although the same coating dispersions were applied for each series.

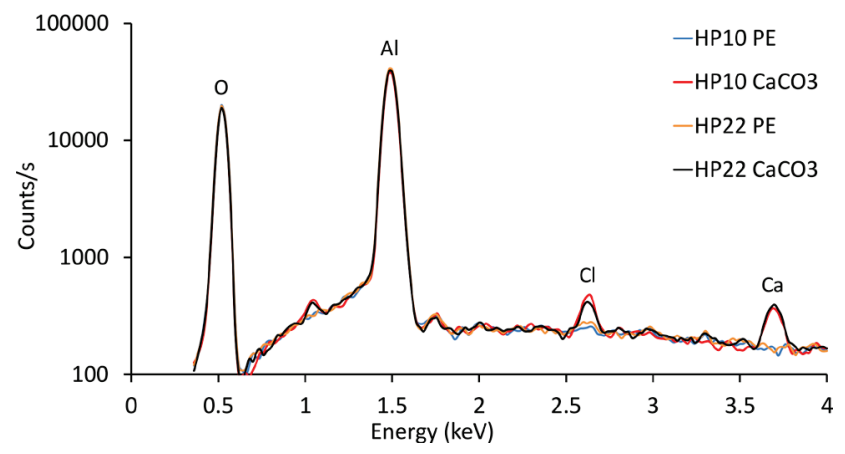

Fig. 4 Surface composition of absorption coatings, on top of a PE- or $\mathrm{CaCO}_{3}$ precoating (SEM-EDS). The surface of papers with $\mathrm{CaCO}_{3}$ precoating contains detectable amounts of $\mathrm{Cl}$ and $\mathrm{Ca}$. Logarithmic scale has been used to highlight the small concentrations of $\mathrm{Cl}$ and $\mathrm{Ca}$.

Surface $\mathrm{pH}$ measurements showed that the absorption coatings on the PE precoated series were acidic with a surface $\mathrm{pH}$ of $4.3-4.8$, while the $\mathrm{CaCO}_{3}$ precoating rendered the coatings slightly alkaline with a pH of 7.1-8.3 (Supplementary Table S6).

\section{Sintering}

Fig. 5 shows microscope images of printed conductors on a selection of active papers, and on the comparison substrates. All substrates allowed a good geometric definition of the conductors, with smooth edges. The conductor width was in the range of $420-450 \mu \mathrm{m}$ on all substrates except for the HP10/PE paper, on which the width was closer to $500 \mu \mathrm{m}$. It is possible that reduced surface roughness, reduced absorption rate and increased surface energy, all contribute slightly to the larger ink spreading on the HP10/PE compared to the other active papers. Although we did not confirm it, slower absorption is likely to result from the more dense pore structure, and higher surface energy is likely to result from the smaller coating pigments. Note that the slow-absorbing LWC paper and the nonabsorbing PET substrate allowed good print definition as well. We can conclude that these have a well matched surface energy for the ink. Paper coating irregularities affected the films, but were small enough to allow film continuity.

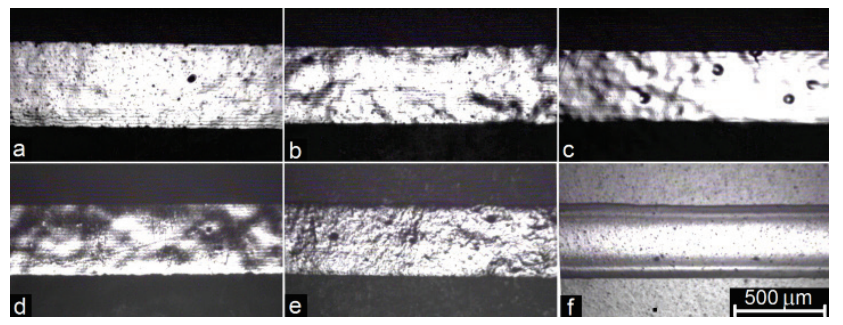

Fig. 5 Inkjet-printed AgNP conductors on active papers and comparison substrates (optical microscopy). All substrates allowed a good printing definition with a comparable conductor width. a) HP10/PE. b) HP10/CaCO3. c) HP22/PE. d) HP22/CaCO3. e) LWC paper. f) PET substrate.

Fig. 6a shows the sintering behavior of the AgNP films on the customdesigned papers. As expected, for all papers, the resistivity decreased when the sintering temperature was raised. With the PE precoating series, the resistivity was in the order of 100-1000 RBS (resistivity of bulk silver, RBS $=1.59 \cdot 10^{-8} \Omega \mathrm{m}$ ) at $60{ }^{\circ} \mathrm{C}$, but decreased exponentially to below $10 \mathrm{RBS}$ at $180{ }^{\circ} \mathrm{C}$. With the $\mathrm{CaCO}_{3}$ precoating, the sintering assisting effect was stronger, giving a resistivity of 20-200 RBS at 60 ${ }^{\circ} \mathrm{C}$ that decreased to $4-8 \mathrm{RBS}$ at $180{ }^{\circ} \mathrm{C}$. It is evident that the $\mathrm{CaCO}_{3}$ precoating increased the effectiveness of the low-temperature sintering. The active coatings clearly assisted low-temperature sintering of the AgNP films. Fig. $6 b$ shows comparison results on a PET substrate. On the PET substrate, the films had a very high resistivity until heated to at least $150{ }^{\circ} \mathrm{C}$. Interestingly, the resistivity was notably affected by the characteristic pore radius, so that a larger pore radius resulted in a larger film resistivity. The greatest impact of the pore radius was clearly seen for low sintering temperatures. However, as the sintering temperature was raised, the impact of the pore radius vanished. This is seen as converging curves at $180{ }^{\circ} \mathrm{C}$ (Fig. 6a). The pore radius dependence was less evident for the $\mathrm{CaCO}_{3}$ series, which had a more notable chemical sintering assisting effect. 

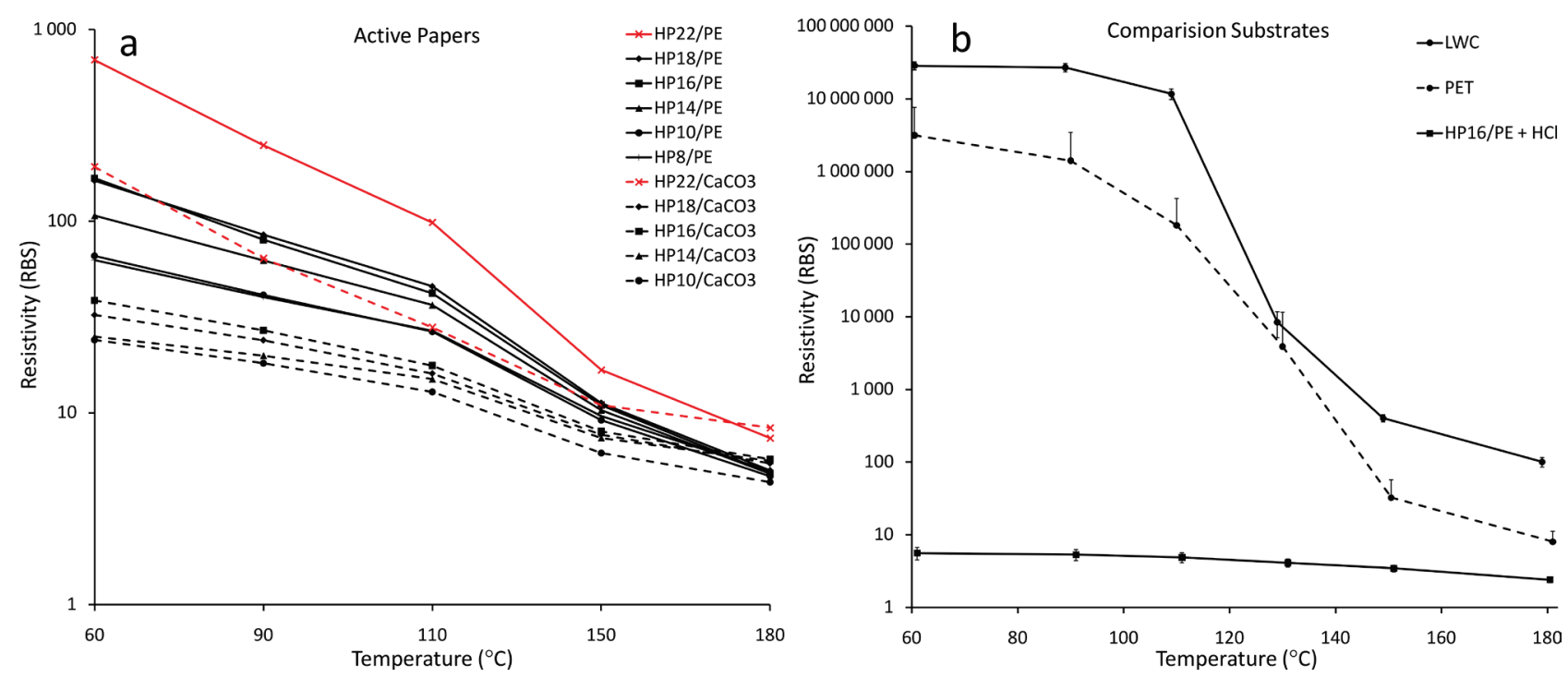

Fig. 6 Resistivity of conductors, printed on the custom papers and on the comparison substrates. a) Custom mesoporous papers. Solid lines represent the PE series and dashed lines represent the $\mathrm{CaCO}_{3}$ series. The $\mathrm{CaCO}_{3}$ precoating increased the effectiveness of the low-temperature sintering. Error bars omitted for visual clarity. b) Conductors on a PET film and a LWC paper had a very high resistivity at low temperature. Treating a HP16/PE paper with extra chloride greatly enhanced its sintering assisting ability. RBS=resistivity of bulk silver. The error bars represent \pm 1 standard deviation.

The influence of the coating pore radius is interesting. It is possible that increases in pore size, and corresponding high-frequency surface roughness, may impair the packing regularity of the AgNP film. In that case, a larger number of gaps and voids would result, decreasing the total number of percolation paths and increasing the film resistivity. Fig. 7 shows a conceptual image representing this hypothesis. When there is a mechanism of sintering, either by chemical interaction or external heating, the eventual aggregation, neck-forming and coalescence of NPs should reduce the importance of the initial packing. This hypothesis is consistent with the experimental results, which show a reduced influence of pore size when either the sintering temperature, or the effectiveness of the sintering agent, is increased. Apparently, increased effectiveness of a chemical sintering agent reduces the pore size dependence, similar to the effect of raising the sintering temperature.

One difference between the PE- and the $\mathrm{CaCO}_{3}$ precoated series was that the $\mathrm{CaCO}_{3}$ series had presence of $\mathrm{Ca}$, as well as a higher concentration of $\mathrm{Cl}$ near the surface, as revealed by EDS analysis. Further, there was a difference in $\mathrm{pH}$ due to the presence or absence of $\mathrm{Ca}$. To examine the effect on sintering caused by a coating presence of $\mathrm{Ca}$ and $\mathrm{Cl}$, we utilized 1) a magazine paper type (LWC) with a top coating containing $\mathrm{CaCO}_{3}$ (but no $\mathrm{Cl}$ ) and 2) The HP16/PE paper, additionally treated with $0.1 \mathrm{M} \mathrm{HCl}$. Fig. $6 \mathrm{~b}$ shows that the LWC $\mathrm{CaCO}_{3}$ coating does not assist sintering since the films have a very high resistivity. Therefore, neither $\mathrm{Ca}^{2+} / \mathrm{CO}_{3}{ }^{2-}$, nor the raised $\mathrm{pH}$ value, likely plays any significant role in the improved sintering assistance observed with the $\mathrm{CaCO}_{3}$ precoating. This is also indicated by the flocculation tests, where $\mathrm{CaCO}_{3}$ did not flocculate a diluted dispersion of the ink (Supplementary Fig. S7). However, the $\mathrm{HCl}$ treated HP16/PE assisted low-temperature sintering much more effectively than the untreated HP16/PE (Fig. 6). This confirms that chloride has a key role in the assisted sintering.

The colloidal stability tests of diluted dispersions revealed that flocculation occurred only for $\mathrm{pH}<2.4$ and for $\mathrm{pH}>12$. The effective stability in this large $\mathrm{pH}$ range suggests that the ink is sterically
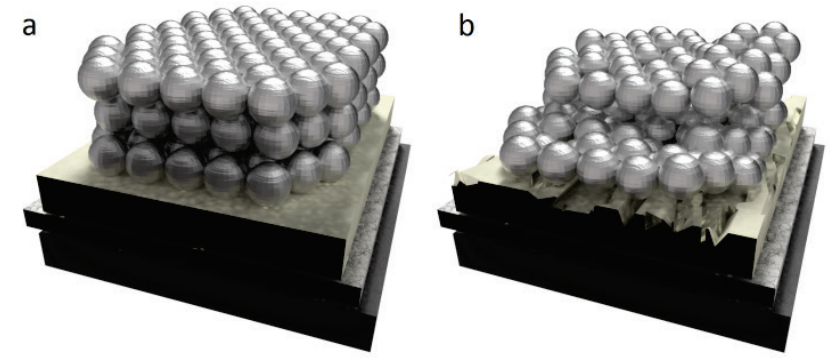

Fig. 7 Schematic image showing the proposed influence of low amplitude, high frequency surface roughness (computer rendering). a) A smooth coating surface allows a more effective packing of NPs. b) An increase in roughness impairs the packing and decreases the density of current percolation paths.

stabilized with a nonionic polymer ${ }^{25}$. The presence of cations, particularly divalent ions such as $\mathrm{Ca}^{2+}$, typically destabilize electrostatic- and electrosteric systems, but have little influence on sterically stabilized systems ${ }^{25}$. Measuring turbidity, neither the addition of $\mathrm{CaCO}_{3}, \mathrm{Na}_{2} \mathrm{CO}_{3}$ or $\mathrm{NaHCO}_{3}$ had any noticeable impact on the colloidal stability at $0.01 \mathrm{M}$ salt concentration, which is consistent with the assumption of a steric stabilization. However, the impact of $\mathrm{CaCl}_{2}$ was large. Flocculation occurred at a concentration of $0.01 \mathrm{M}$ $\mathrm{CaCl}_{2}$, indicating that the presence of $\mathrm{Cl}^{-}$effectively destabilized the dispersion (Supplementary Fig. S7). Therefore it can be expected that $\mathrm{Cl}$ contained in the coating, if it migrates into the AgNP film in a sufficient concentration, should impose aggregation on the substrate and therefore assist sintering. With the paper designs demonstrated here, the incorporated coating chloride indeed assisted the sintering at low temperatures. Fig. 8 shows top views of the AgNP film morphology after room temperature drying. Note that the $\mathrm{CaCO}_{3}$ precoating further enhances the effect of the active coating, and induces morphological transformation of the AgNP film already at room temperature. 


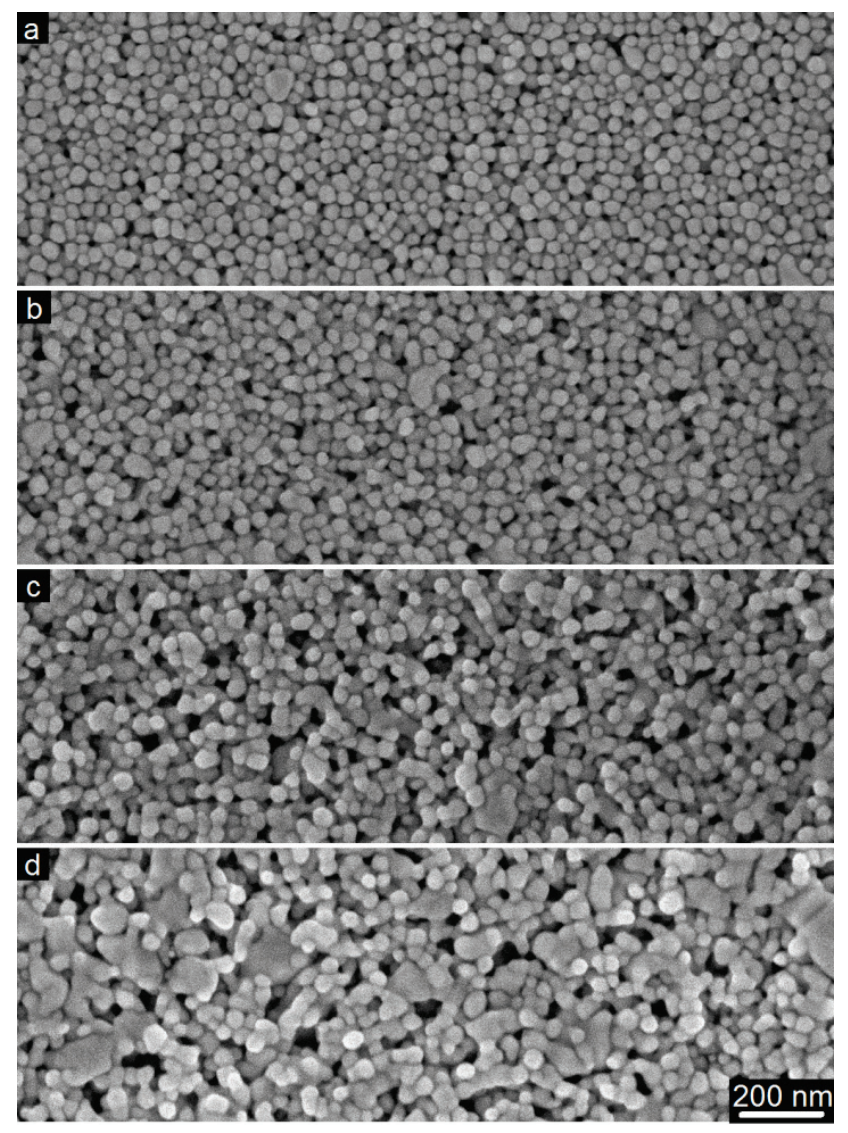

Fig. 8 AgNP films on active papers after room temperature drying (SEM). The $\mathrm{CaCO}_{3}$ precoating enhances the effect of the sintering agent, imposing morphological change of the conductive network. a) HP10/PE. b) HP22/PE. c) HP10/CaCO3. d) HP22/CaCO 3.

Fig. $8 a$ and $b$ show the AgNP film on PE-precoated papers using HP10 and HP22 coatings, respectively. There is no visible neck-formation with the PE precoating. Note that on the HP10 coating, the NPs appear to be more effectively packed, while there is more gaps in the film with the HP22 coating. This is consistent with the idea in Fig. 7. Fig. $8 \mathrm{c}$ and $\mathrm{d}$ show the film on the corresponding $\mathrm{CaCO}_{3}$ precoated papers. Here, the onset of room-temperature sintering is evident with a visible neck-formation. The larger gaps in the films on the $\mathrm{CaCO}_{3}$ precoated papers is presumably not due to the initial NP packing. The size of the largest gaps has increased due to the enhanced sintering. Coalescence and neck-forming of individual particles implies that the larger voids increase in size, when $\mathrm{Ag}$ is redistributed to bridge smaller voids during sintering. Fig. 9 shows the corresponding cross-sections of AgNP films on the same papers. The films are delaminated from the coatings in the images, so that the film underside is visible. Note that the AgNP films appear to be more tightly packed in their lower part, towards the coating. This is most clearly seen for the HP22/PE cross-section (Fig. 9b). The crosssections also indicate a more dense AgNP packing on the HP10 coatings compared with the HP22 coatings. Room-temperature sintering with the $\mathrm{CaCO}_{3}$ precoatings is visible as neck-formation between NPs through the entire thickness of the AgNP film. This is most notable with the $\mathrm{HP} 10 / \mathrm{CaCO}_{3}$ paper (Fig. 9c).
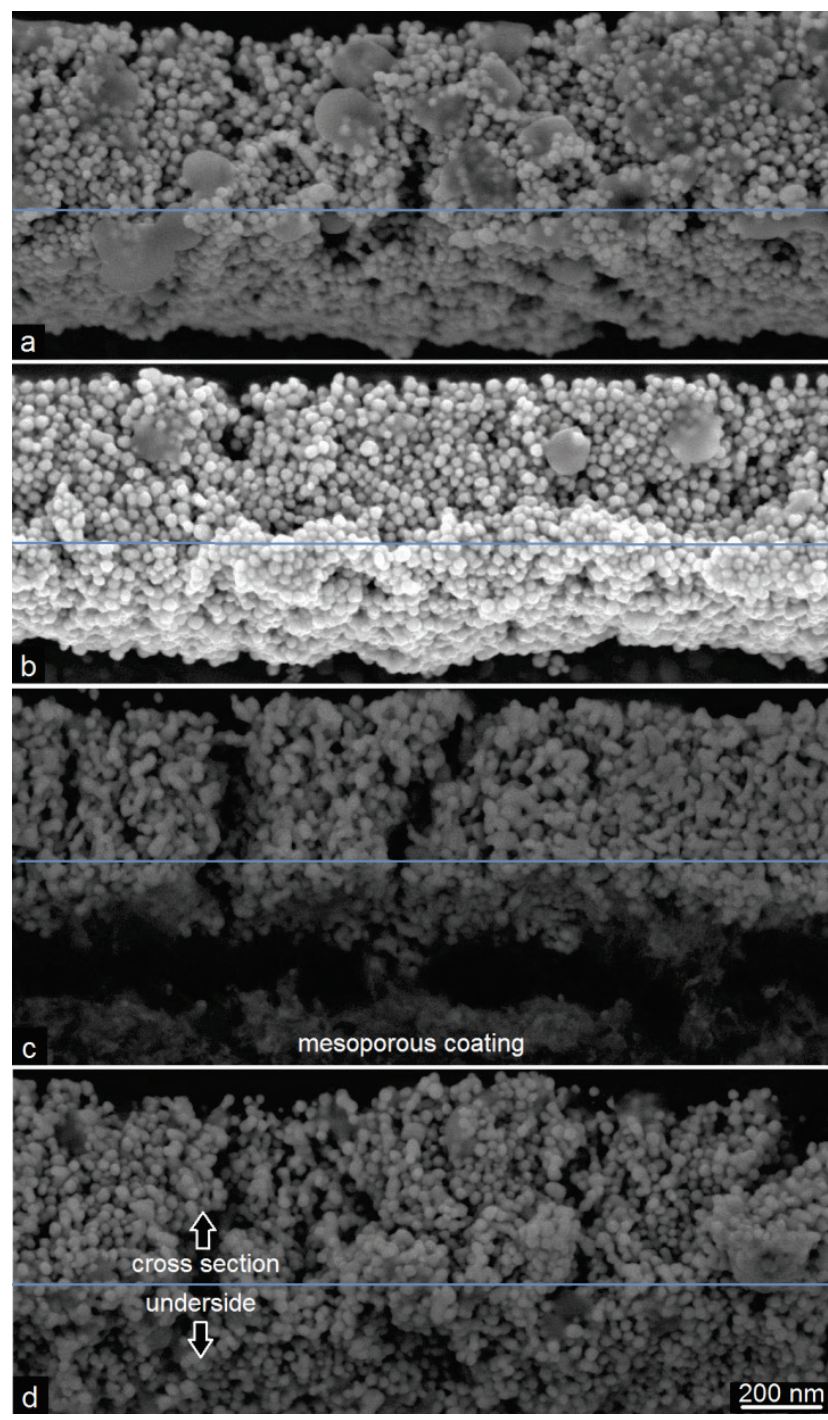

Fig. 9 Cross-sections of AgNP films on active papers after room temperature drying (SEM). Neck-formation between NPs is seen with the $\mathrm{CaCO}_{3}$ precoatings. a) $\mathrm{HP} 10 / \mathrm{PE}$. b) $\mathrm{HP} 22 / \mathrm{PE}$. c) $\mathrm{HP} 10 / \mathrm{CaCO}_{3}$. d) $\mathrm{HP} 22 / \mathrm{CaCO}_{3}$.

Table 1 shows concentrations of relevant elements at the surface of inkjet-printed AgNP films, using $\mathrm{PE}-$ or $\mathrm{CaCO}_{3}$ precoating. Note that the $\mathrm{Cl}$-concentration in the AgNP films is much higher than the $\mathrm{Cl}$ concentration in the coatings. This suggests that $\mathrm{Cl}^{-}$ions migrate from the coating into the AgNP film during the solvent absorption and film formation. Fig. 10 shows a conceptual image illustrating this process. Note that in contrast, Table 1 does not suggest any migration and concentration of $\mathrm{Ca}^{2+}$.

Table 1. Concentration of elements at the surface of inkjet-printed AgNP films. HP14 coating (XPS, Atomic \%). Small concentrations of $\mathrm{Cl}$ and $\mathrm{Ca}$ are present at the surface of the papers with $\mathrm{CaCO}_{3}$ precoating. After deposition, the $\mathrm{Cl}$ concentration is much higher in the AgNP films, suggesting that $\mathrm{Cl}$ ions migrate into the AgNP film during the solvent absorption and film formation.

\begin{tabular}{lllll}
\hline $\begin{array}{l}\text { AgNP film } \\
(\mathrm{PE})\end{array}$ & $\begin{array}{l}\mathrm{AgNP} \text { film } \\
(\mathrm{CaCO})\end{array}$ & $\begin{array}{l}\text { Paper surface } \\
(\mathrm{PE})\end{array}$ & $\begin{array}{l}\text { Paper surface } \\
\left(\mathrm{CaCO}_{3}\right)\end{array}$ \\
\hline $\mathrm{Cl}$ & 1.2 & 2.7 & Below detection limit & 0.25 \\
$\mathrm{Ca}$ & 0 & 0.28 & 0 & 0.23
\end{tabular}




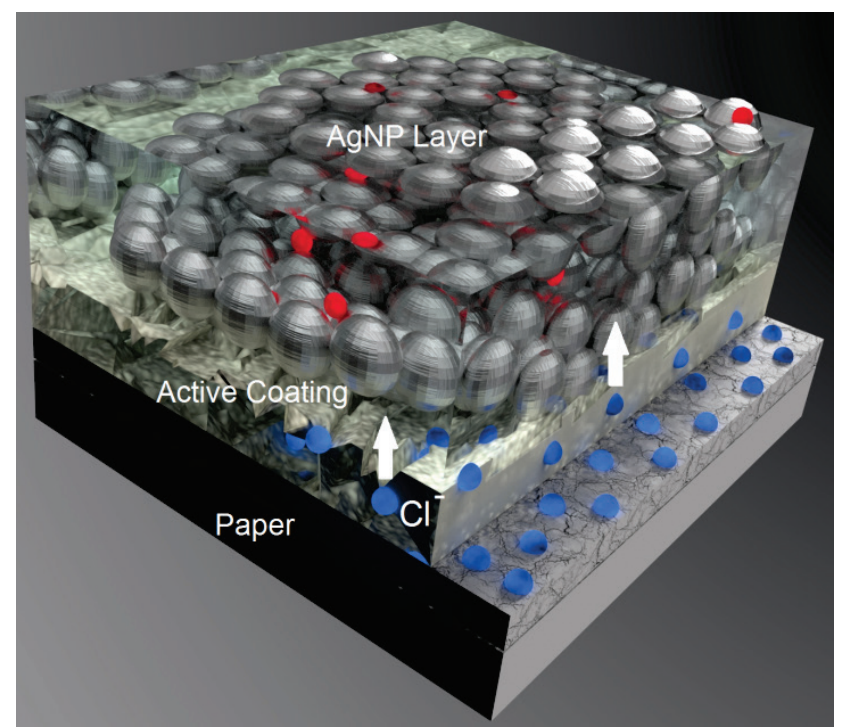

Fig. 10 Schematic image showing the principle of the active papers (computer rendering). A small amount of chloride is contained in the coating as a sintering agent. During the deposition of the AgNP dispersion and absorption of the carrier fluid, $\mathrm{Cl}$ ions migrate into the AgNP film and react with the AgNP matrix to assist the sintering.

It has been shown previously that the physical structure of paper coatings has a profound influence of the film formation and the resulting conductivity of inkjet-printed metal NP films ${ }^{26,27}$. It was proposed that surface roughness and pore size distribution are critical parameters for the conductive film formation. It was further suggested that the impact is small, as long as surface roughness amplitudes and pore sizes are much smaller than the thickness of the dry film. In other studies, chemical properties of the surfaces have been shown to have a large effect on the resulting conductivity ${ }^{28-30}$. Here, the physical film formation is not much affected, but the stabilizing molecules attached to the NPs may change conformation and charge, or even be de-attached depending on the coating surface chemistry. This will affect the steric- and/or electrostatic repulsion and therefore the average particle spacing as the film dries. Smaller particle spacing will increase the number of contact points that allow electrons to pass, and therefore increase electrical conductivity of the NP film. Chemical compounds present on the surface may also directly react with metal NPs or free ions. Here we have utilized a small concentration of chloride integrated into mesoporous paper coatings, to achieve a chemically assisted low-temperature sintering. During the quick absorption of the ink solvent and setting of the NP film, $\mathrm{Cl}$ ions apparently migrates into the film, increasing the concentration and destabilizing the organic ligands. The mechanism of AgNP matrix destabilization by $\mathrm{Cl}$ ions has been established earlier in various studies ${ }^{31-33}$.

In this study, all coatings had a surface roughness and characteristic pore size that was small compared to the thickness of the ink film. This suggests that the macroscopic film formation should not be much affected and the resistivity should remain fairly similar across the variations in pore size. This assumption held true only when there was sufficient sintering, either by externally applied heat, or by a suitable surface chemistry. When there was less effective sintering, small increases in characteristic pore size (and related high-frequency surface roughness) notably affected the AgNP film resistivity.

We may regard an unsintered metal NP film as a structurally disordered system, where the resistivity can be modeled by percolation theory. The resistivity $\rho$ of a 3-dimensional percolation network is given by $\rho \sim\left(p-p_{c}\right)^{-2}$ where $p$ is the probability for $a$ conductive path in each lattice point. The percolation threshold $p_{c}$ is the probability, below which the network will be insulating. When $p$ is increased, the average size of the model clusters increases. At the threshold $p_{c}$, a large cluster forms, connecting opposite edges of the lattice. When $p$ is increased further, the density of the large cluster increases. Increasing $\mathrm{p}$ in the percolation model can be visualized to correspond to the coalescence and clustering of NPs in the physical films. Increasing the extent of sintering (such as the temperature) will increase the size of the clusters, and at some point, the film will be transformed into a porous bulk metal and no longer be well described as a disordered system.

Using the active coatings significantly assisted low-temperature sintering, compared to the PET film and LWC paper. The observation that the porous $\mathrm{CaCO}_{3}$ precoating further enhanced the effect of lowtemperature sintering is likely due to its impact on the surface chemistry, as the $\mathrm{Cl}$ concentration near the surface was higher. The $\mathrm{CaCO}_{3}$ precoating also raised the $\mathrm{pH}$ significantly, although the $\mathrm{pH}$ effect on the sintering is probably minor, as indicated by the flocculation experiments and the results on the LWC paper. Moreover, the porous $\mathrm{CaCO}_{3}$ precoating increased the absorption rate of the papers. We observed that the printed films dried instantly at room temperature on the papers with the $\mathrm{CaCO}_{3}$ precoating, but were wet for several minutes with the PE precoating. It is likely that the absorption rate affects the chemical sintering process. This is because the absorption rate sets the time frame for the liquid phase ink-substrate interaction, including the interactions of sintering agents, ink free ions and stabilizing polymers. The specific influence that the increased absorption rate may have on the sintering in this system, remains unknown. However, the instant-drying behavior enabled by the $\mathrm{CaCO}_{3}$ precoating, is clearly beneficial in a high-speed roll-to-roll manufacturing environment.

Increased sintering temperature notably decreased the differences in resistivity, both with respect to surface chemistry and physical surface properties (roughness/pore size). At $180^{\circ} \mathrm{C}$ the differences mostly vanished. The usefulness of chemical sintering assistance is obvious. Here we have implemented the concept in highly absorbing coated paper substrates, possibly contributing to extended possibilities for future flexible electronics manufacturing. 


\section{Conclusions}

We have demonstrated custom-made active coated papers and used them to achieve low-temperature sintering of inkjet-printed silver films. We have evaluated important construction parameters such as coating pore size and precoating type. We demonstrated two main concepts that greatly affected low-temperature sintering. 1) Incorporating an active sintering agent in the coating recipe. 2) Adapting the precoating. Each of those concepts, or a combination, may be utilized to tailor the paper properties for a specific AgNP dispersion. Paper substrates offer not only advantages such as environmental friendliness and fast ink absorption capability, but also great possibilities for adaptation and tailoring in design. As we have shown here, tailored coated papers may reduce or remove the need for explicit sintering. This suggests high potential for roll-to-roll fabrication of printed electronics.

\section{Acknowledgements}

We gratefully acknowledge financial support from the Kempe foundations, the Swedish agency for economic and regional growth and the Gunnar Sundblad research foundation. The funding sources had no involvement in this article. We wish to thank Felix Schoeller Group for materials and support during manufacturing of the papers. For SEM imaging, we acknowledge Nikki Lee and the Umeå Core Facility for Electron Microscopy (UCEM). We acknowlegde Andrey Shchukarev at Umeå University for XPS characterization. We thank Jonas Örtegren, Magnus Hummelgård, Dan Bylund and Joakim Bäckström at the Mid Sweden University for contributions with materials and characterization. Finally we acknowledge Joachim Wollschläger and Lorenz Walder at the university of Osnabrück for supervision of Anna Schuppert during her time at Felix Schoeller Group.

\section{References}

1 C. N. Hoth, P. Schilinsky, S. A. Choulis and C. J. Brabec, Nano Lett., 2008, 8, 2806-2813.

2 B. Li, S. Santhanam, L. Schultz, M. Jeffries-El, M. C. Iovu, G. Sauvé, J. Cooper, R. Zhang, J. C. Revelli, A. G. Kusne,

J. L. Snyder, T. Kowalewski, L. E. Weiss, R. D. McCullough, G. K. Fedder and D. N. Lambeth, Sens. Actuators, B, 2007, 123, 651-660

3 T. Shimoda, K. Morii, S. Seki and H. Kiguchi, MRS Bull., 2003, 28, 821-827.

4 V. Subramanian, J. M. J. Frechet, P. C. Chang, D. C. Huang, J. B. Lee, S. E. Molesa, A. R. Murphy, D. R. Redinger and S. K. Volkman, Proc. IEEE, 2005, 93, 1330-1338.

5 J. L. Cuya Huaman, K. Sato, S. Kurita, T. Matsumoto and B. Jeyadevan, J. Mater. Chem., 2011, 21, 7062-7069.

6 N. Rouhi, D. Jain and P. J. Burke, ACS Nano, 2011, 5, 84718487.

7 X. Ding, Y. Li, D. Wang and Q. Yin, Ceram. Int., 2004, 30, 1885-1887.

8 C. J. Sambucetti, IEEE Trans. Magn., 1980, 16, 364-367.

9 V. Fakhfouri, N. Cantale, G. Mermoud, J. Y. Kim, D. Boiko,

E. Charbon, A. Martinoli and J. Brugger, in Micro Electro

Mechanical Systems, 2008, IEEE 21st International Conference on MEMS 2008, 2008, pp. 407-410.

10 M. F. Mabrook, C. Pearson and M. C. Petty, Appl. Phys.

Lett., 2005, 86, 013507.
11 E. A. Roth, T. Xu, M. Das, C. Gregory, J. J. Hickman and T. Boland, Biomaterials, 2004, 25, 3707-3715.

12 T. Öhlund, J. Örtegren, H. Andersson and H.-E. Nilsson, in NIP \& Digital Fabrication Conference, 2010, pp. 309-313.

13 A. R. Studart, E. Amstad and L. J. Gauckler, Langmuir, 2006, 23, 1081-1090.

14 K. Chou and C. Ren, Mater. Chem. Phys., 2000, 64, 241246.

$15 \mathrm{H}$. Yoon and J. Jang, Adv. Funct. Mater., 2009, 19, 15671576.

16 K. Kordás, T. Mustonen, G. Tóth, H. Jantunen, M. Lajunen, C. Soldano, S. Talapatra, S. Kar, R. Vajtai and P. M. Ajayan, Small, 2006, 2, 1021-1025.

17 L. Huang, Y. Huang, J. Liang, X. Wan and Y. Chen, Nano Res., 2011, 4, 675-684.

18 Y. Li, Y. Wu and B. S. Ong, J. Am. Chem. Soc., 2005, 127, 3266-3267.

19 L. Youngil, C. Jun-rak, L. Kwi Jong, E. S. Nathan and K. Donghoon, Nanotechnology, 2008, 19, 415604.

20 D. Li, D. Sutton, A. Burgess, D. Graham and P. D. Calvert, J. Mater. Chem., 2009, 19, 3719-3724.

21 G. Shaker, S. Safavi-Naeini, N. Sangary and M. M.

Tentzeris, IEEE Antenn. Wireless Propag. Lett., 2011, 10, 111114.

22 H. Andersson, A. Manulskij, S. Haller, M. Hummelgård, J.

Siden, C. Hummelgård, H. Olin and H-E Nilsson,

Nanotechnology, 2014, 25, 094002.

23 A. Sridhar, D. J. van Dijk and R. Akkerman, Thin Solid Films, 2009, 517, 4633-4637.

24 W. A. Damrau and J. C. Gauss, Patent US4250211, 1981.

25 A. M. E. Badawy, T. P. Luxton, R. G. Silva, K. G. Scheckel, M. T. Suidan and T. M. Tolaymat, Environ. Sci. Technol.,

2010, 44, 1260-1266.

26 T. Öhlund, J. Örtegren, S. Forsberg and H.-E. Nilsson, Appl.

Surf. Sci., 2012, 259, 731-739.

27 P. Ihalainen, A. Määttänen, J. Järnström, D. Tobjörk,

R. Österbacka and J. Peltonen, Ind. Eng. Chem. Res., 2012,

51, 6025-6036.

28 S. Magdassi, M. Grouchko, O. Berezin and A. Kamyshny, ACS Nano, 2010, 4, 1943-1948.

29 A. Mark, L. Jaakko, V. Marja, A. Ari and M. Tomi, Nanotechnology, 2010, 21, 475204.

$30 \mathrm{H}$. Andersson, A. Manuilskiy, C. Lidenmark, J. Gao,

T. Öhlund, S. Forsberg, J. Örtegren, W. Schmidt and

H. E. Nilsson, Nanotechnology, 2013, 24, 455203.

31 W. Zapka, W. Voit, C. Loderer and P. Lang, NIP \& Digital Fabrication Conference, 2008, 2008, pp. 906-911.

32 M. Grouchko, A. Kamyshny, C. F. Mihailescu, D. F. Anghel and S. Magdassi, ACS Nano, 2011, 5, 3354-3359.

33 M. Layani, M. Grouchko, S. Shemesh and S. Magdassi, J. Mater. Chem., 2012, 22, 14349-14352. 